\title{
INTEGRATED GRID INVERTER WITH FREQUENCY CONTROL SCHEME FOR WIND MILL APPLICATIONS
}

\author{
Vikramarajan Jambulingam \\ Electrical and Electronics Engineering, VIT University, India
}

\begin{abstract}
The wind power is also on the popular form of energy generation. The frequency mismatch is one of the major crisis under the power quality issues when the renewable energy system is connected to the grid. Therefore the main objective of this project is to equalize the number of cycles per second in the grid as well as number of cycles per second in the inverter under different load conditions at various time periods. Hence the proposed project regarding frequency control scheme using grid integrated inverter for wind mill applications effectively compromises the drawbacks. Mainly the frequencies mismatch in the existing systems by equalizing the frequencies difference between the grid as well as the inverter.
\end{abstract}

Keywords: wind power, frequency control scheme

\section{INTRODUCTION}

Wind is a copious vital source of energy which is complimentary and a fabulous gift of Mother Nature. Joselin Herbert [1] explained the analysis of the performance, failure and reliability, as well as a spare parts analysis have been conducted for a wind farm.Narasimhan Santhanam [2] explained the success story about Indian Wind power and also its poor grid system. G.M. Joselin Herbert [3] explained the existing performance and reliability evaluation models, various problems related to wind turbine components. M.R. Nouni [4] explained the economic evaluation of small wind electric generator (SWEG) projects for providing decentralized power supply in remote locations. Muhammad Khalid [5] explained the aim of this study is to design a controller based on model predictive control (MPC) theory to smooth wind power generation along with the controlled storage of the wind energy in batteries in presence of variety of constraints.

Md. Enamul Haque [6] explained a novel control strategy for the operation of a direct-drive permanent-magnet synchronous-generator-based stand-alone variable-speed wind turbine. Gillion Lalor [7] explained the frequency control and wind turbine technologies. Inigo Martinez de Alegraa [8] explained the main problems of the connection of wind farms to the grid and how the grid codes must be adapted in order to integrate wind power generation capacity without affecting the quality and stability of the grid and summarizes the grid codes that have already been modified to incorporate high levels of wind power.

Hence the proposed project regarding frequency control scheme using grid integrated inverter for wind mill applications is designed to effectively compromise the drawbacks.

\section{BLOCK DIAGRAM OF PROPOSED SYSTEM}

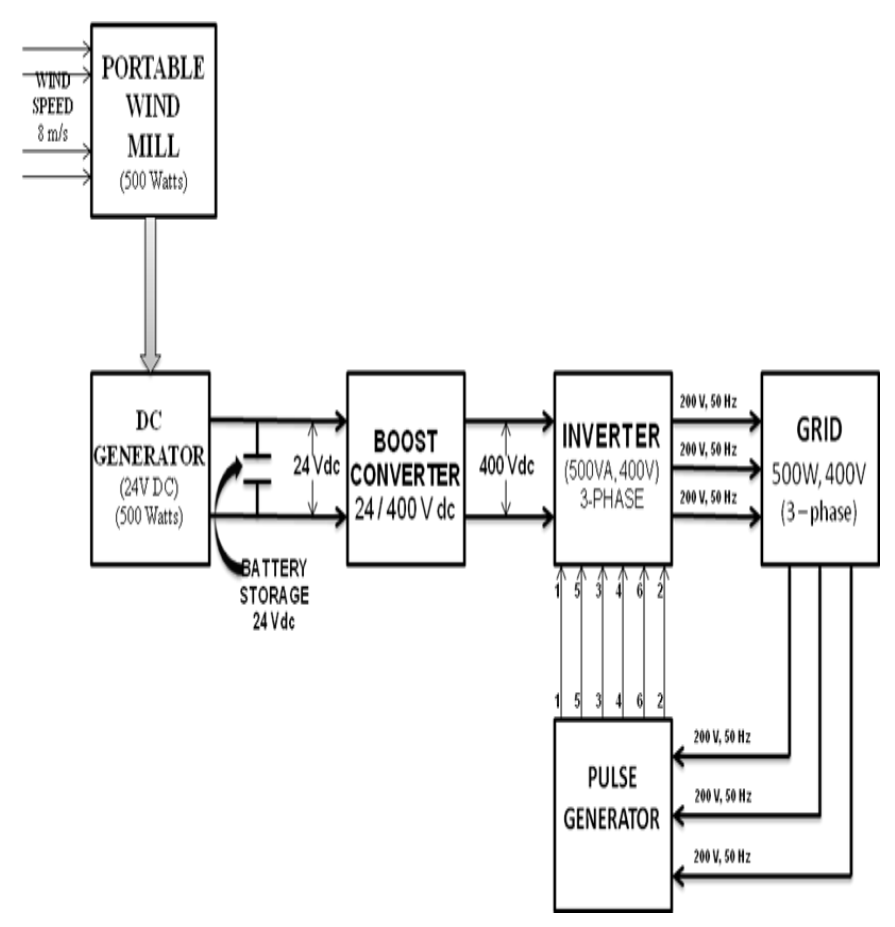

Fig 1 Block diagram for proposed system

The proposed system block diagram is shown in Figure 1. It is a closed loop system which consists of an AR-500W portable wind mill coupled with a 24 volt dc generator and is connected to 24 volt battery storage. Thus the wind energy is converted 
into electrical energy and this energy is collected in a battery bank and stored. The 24 volt de which is stored in the battery and it is regulated to 400 volt dc via boost converter. This 400 volt dc output from the boost converter is fed as an input to the three phase inverter module which converts fixed dc voltage into three phase variable ac voltage as an output. The three phase output ac voltage from the inverter is connected along with the grid. A pulse generator gets the input voltage and frequency from the grid and delivers six different pulses to the six switches S1, S2, S3, S4, S5 and S6 of the inverter.

The grid side voltage as well as its frequency varies in accordance to the different loads connected besides the grid. So, whenever there is a change in voltage and frequency at the grid side, then the pulse generator varies with the pulses delivered to the inverter switches accordingly. This as a result changes the inverter output voltage and frequency just as same as the grid side voltage and frequency. Hence the inverter output frequency is mapped with the grid side frequency and thus the setback in the foregoing method is met through this proposed system methodology.

\subsection{Generator}

A 24 volt de generator of power 500 Watts with $300 \mathrm{rpm}$ of speed is used for this proposed renewable energy system. The dc generator converts the input mechanical energy into an electrical energy output.

Table.1 Design specification and circuit parameters

\begin{tabular}{|l|l|}
\hline \multicolumn{2}{|l|}{ GENERATOR } \\
\hline TYPE & DC Generator \\
\hline VOLTAGE (V) & 24 Volt DC \\
\hline WATTS @ RATED & \\
WIND SPEED & 500 Watts \\
\hline SPEED RPM (nominal) & 300 \\
\hline
\end{tabular}

With the help of MATLAB simulink environment, the simulation of a dc generator is done for the given ratings as in table 1 . The simulink provides a dc machine block, in which the parameters are set as per the requirements. A dc voltage source is connected with the field winding provided in the block. The dc machine is made to run at the speed of $300 \mathrm{rpm}$, so that, the rated dc voltage ( 24 volts) is derived as an output from the armature winding of the machine.

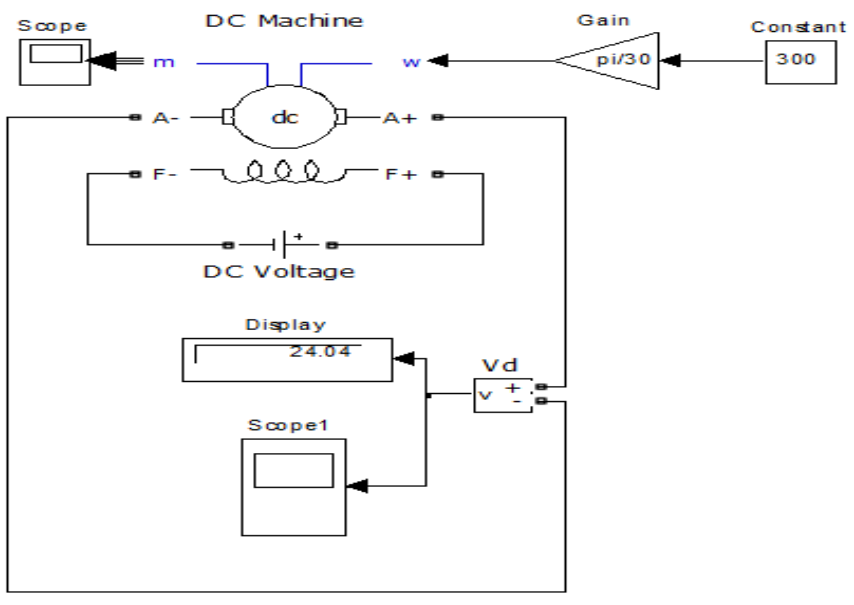

Fig 2 Simulation model of DC generator

\subsection{Boost Converter}

A boost converter (step-up converter) is a DC-to-DC power converter with an output voltage greater than its input voltage.

A boost converter is designed with the help of MATLAB simulink software which is shown in the figure 3. A 24 volt dc source is given as an input to the converter circuit and a 400 volt dc output is regulated from the circuit. As discussed in the above calculations, the inductance and the capacitance values are calculated as per the project requirements. The 400 volt dc output regulated from the boost converter is given as an input to the three phase inverter circuit which will be discussed later. The input and output dc voltage of the boost converter is compared and measured by connecting a scope as shown in figure 3. The simulation results are plotted in the figure 6.4.

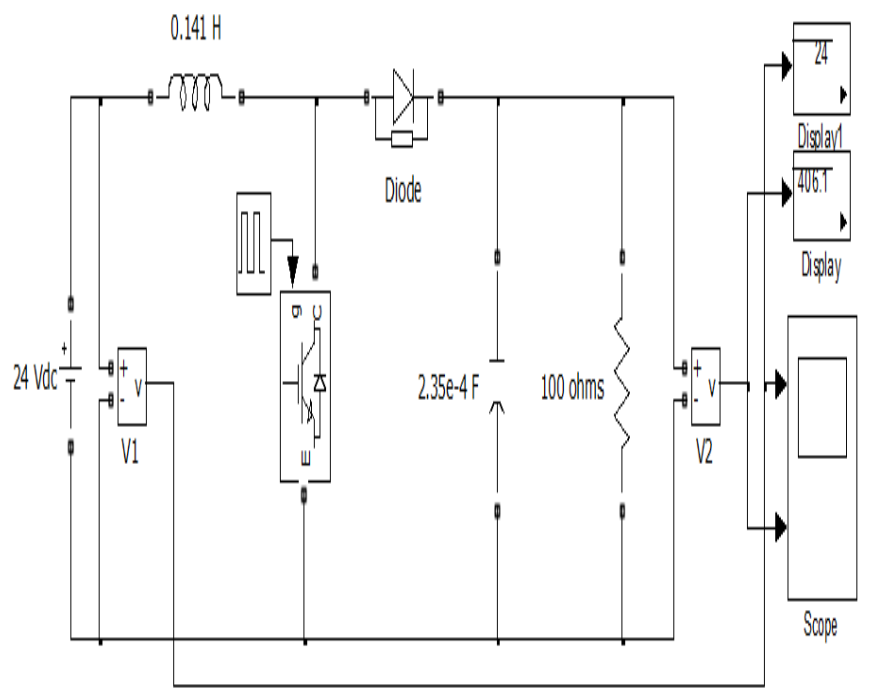

Fig 3 Simulation model of boost converter 


\subsection{Pulse Generator}

Every pulse is produced whenever the output goes high and the sine wave amplitude is greater than the triangular wave generated. Six different pulses are generated and these generated pulses are given as the input to the inverter switches S1, S2, S3, S4, S5 \& S6. Also whenever there is a change in the input signal received from the grid the pulses are generated accordingly with a quicker response which decides the system frequency and changes similar to the grid frequency and thus the system stability is maintained.

Figure 4 illustrates the simulink model for generating a three phase PWM. A three phase input supply of 440 volts and 50 hertz from the grid is compared with the triangular wave which is generated using a repeating sequence. This input sine wave and the generated triangular wave are compared with the help of a relational operator.

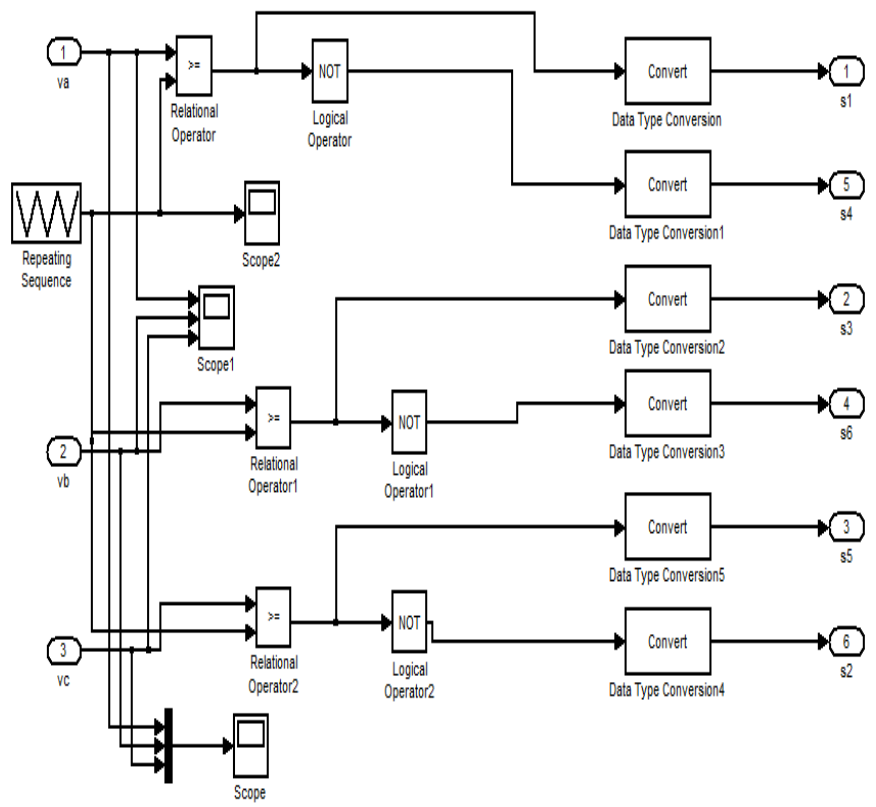

\subsection{Bridge Inverter}

In a three-phase inverter each switch conducts for $180^{\circ}$ of a cycle. IGBT pair in each arm, i.e. T1, T4; T3, T6 and T5, T2 is turned on with a time interval of $180^{\circ}$.

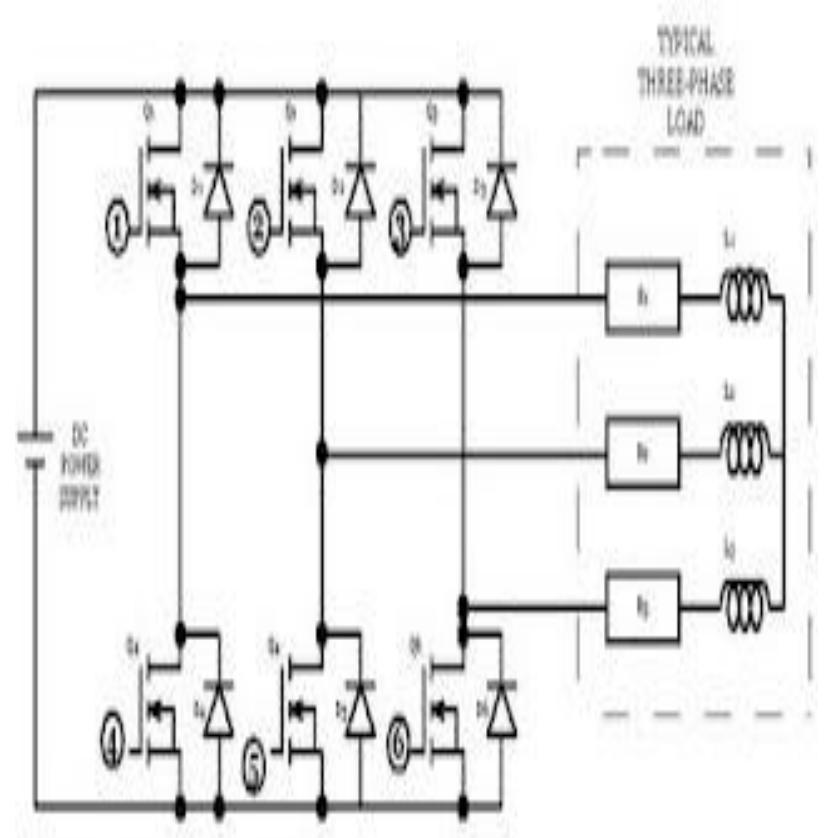

Fig 5 Circuit diagram of three phase bridge inverter

Fig 4 Simulation model of pulse generator

Table 2180 degree mode of conduction with 400 volt dc input

\begin{tabular}{|l|l|l|l|l|l|l|l|}
\hline $\begin{array}{l}\text { FIRING ANGLE } \\
\text { (Degrees) }\end{array}$ & $\begin{array}{l}\text { IGBTS } \\
\text { CONDUCTING }\end{array}$ & $\begin{array}{l}\text { Van } \\
\text { (Volts) }\end{array}$ & $\begin{array}{l}\text { Vbn } \\
\text { (Volts) }\end{array}$ & $\begin{array}{l}\text { Vcn } \\
\text { (Volts) }\end{array}$ & $\begin{array}{l}\text { Vab } \\
\text { (Volts) }\end{array}$ & $\begin{array}{l}\text { Vbc } \\
\text { (Volts) }\end{array}$ & $\begin{array}{l}\text { Vca } \\
\text { (Volts) }\end{array}$ \\
\hline $0-60$ & $5,6,1$ & 133.33 & -266.66 & 133.33 & 400 & -400 & 0 \\
\hline $60-120$ & $6,1,2$ & 266.66 & -133.33 & -133.33 & 400 & 0 & -400 \\
\hline $120-180$ & $1,2,3$ & 133.33 & 133.33 & -266.66 & 0 & 400 & -400 \\
\hline $180-240$ & $2,3,4$ & -133.33 & 266.66 & -133.33 & -400 & 400 & 0 \\
\hline $240-300$ & $3,4,5$ & -266.66 & 133.33 & 133.33 & -400 & 0 & 400 \\
\hline $300-360$ & $4,5,6$ & -133.33 & -133.33 & 266.66 & 0 & -400 & 400 \\
\hline
\end{tabular}


The table 2 is calculated for a supply voltage of Vs $=400$ volt (dc) which is given as an input dc supply and the output dc voltages.Since the 180 degree mode of conduction has better utilization of the switches, it is preferred for obtaining a three phase output voltage according to the variations in the grid side voltage.

The table 2 clearly explains how does the six step three phase inverter operates at different modes and how the $400 \mathrm{vdc}$ output is attained at different time intervals.

\section{INTEGRATED GRID INVERTER}

A three phase grid integrated inverter) is intended with the help of MATLAB graphical user interface software which is shown in figure 6 . The 400 volt dc source is given as an input to the inverter model which is designed with six IGBT's. Each IGBT is triggered with six different pulses delivered from the pulse generator.

The pulse generator receives three phase sine wave signals from the grid. The received three phase sine wave signal is compared with the triangular wave which is generated with the help of a repeating sequence. The repeating sequence block is available in the simulink option. The parameter values of the repeating sequence is set in the parameters block according to the project requirements.

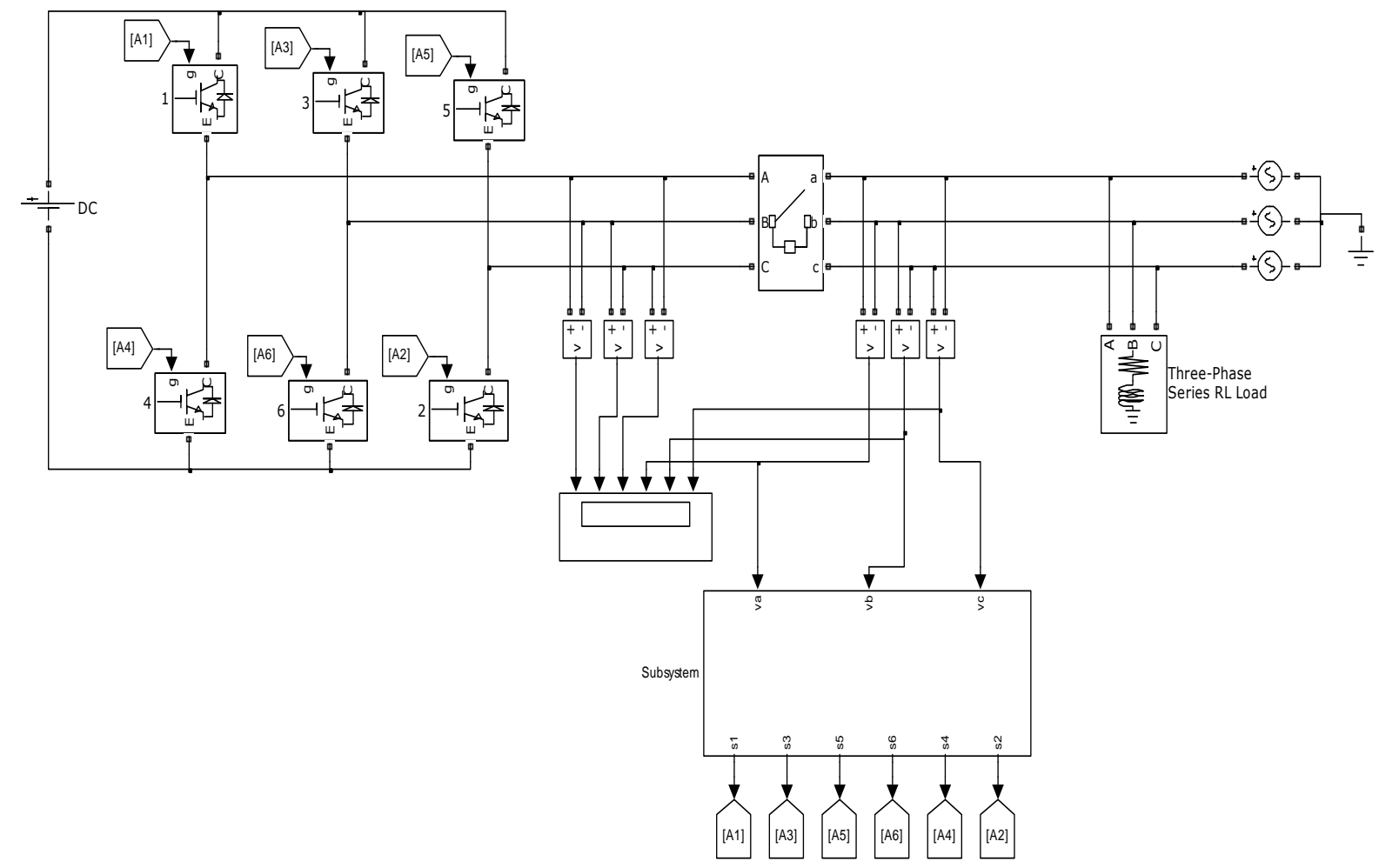

Fig.6. Simulation model of integrated grid inverter

The comparison of these two signals i.e. the sine wave signal and the triangular wave signal, both together generates six different square wave pulses which are given to the inverter switches to operate at different frequencies according to the change in the grid side frequency. So, whenever there is a change in the grid side frequency the triggered pulse from the pulse generator varies, which in order controls the inverter output frequency and hence both the inverter as well as the grid side frequencies shown clearly in the figure 10.

\section{SIMULATION MODEL OF TEST SYSTEM}

The three phase grid supply of 400 volts and 50 Hertz is connected to the inverter output terminals with the help of a three phase breaker as shown in the figure 7 . If the breaker is not connected in between the circuit, then the grid voltage actually starts to supply voltage to the inverter. This makes the inverter circuit to act like a rectifier circuit operation. The mode of operation is reversed. This makes the entire system to 
subside and cause a major impact on the renewable energy system. So in order to avoid such system collapse, a three phase breaker is connected between these circuits.

While there is an increase in the load inductance, then a lagging power factor occurs which cause a change in grid frequency. The frequency deviations under various load conditions taken place in the system.
The change in grid frequency signal is given to the pulse generator which is compared with a reference signal. The compared signals generate six different pulses to the inverter. This operates the inverter for three phase $400 \mathrm{~V}$ ac output with frequency similar to grid frequency. The overall simulation test model of proposed system is designed in MATLAB / SIMULINK as shown in Figure 7.

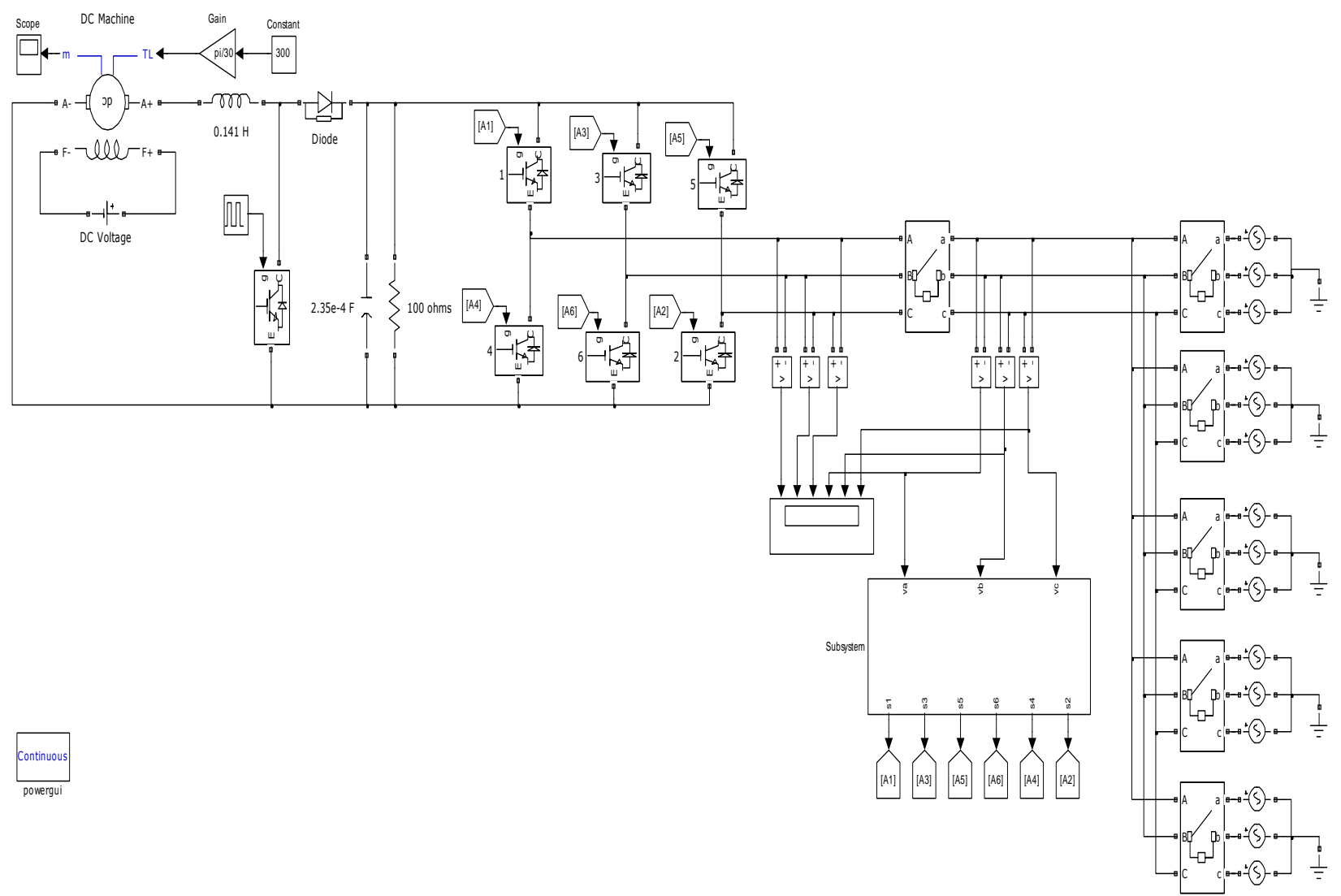

Fig.7. Simulation model overall test system

\section{SIMULATION RESULTS}

The output voltage is measured with the help of a scope as shown in figure 2 . The output dc voltage obtained through simulation is plotted in the figure 8 . The plot clearly displays the simulation result for 24 volts unidirectional (dc) output delivered from the dc generator.

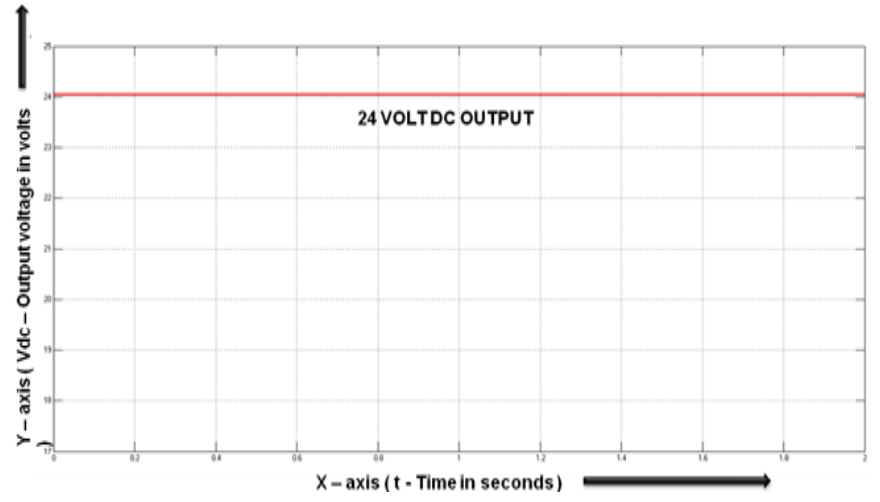

Fig 8 Simulation result of dc generator 


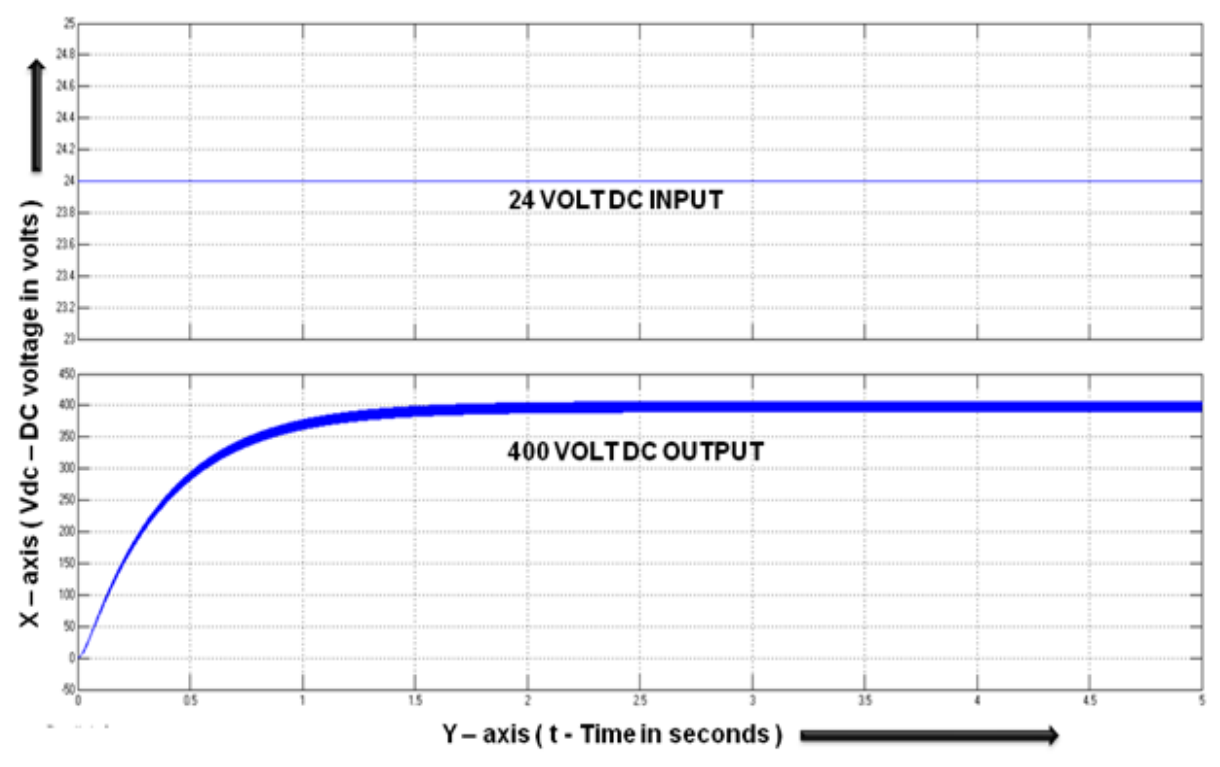

Fig 9 Simulation result of Boost converter

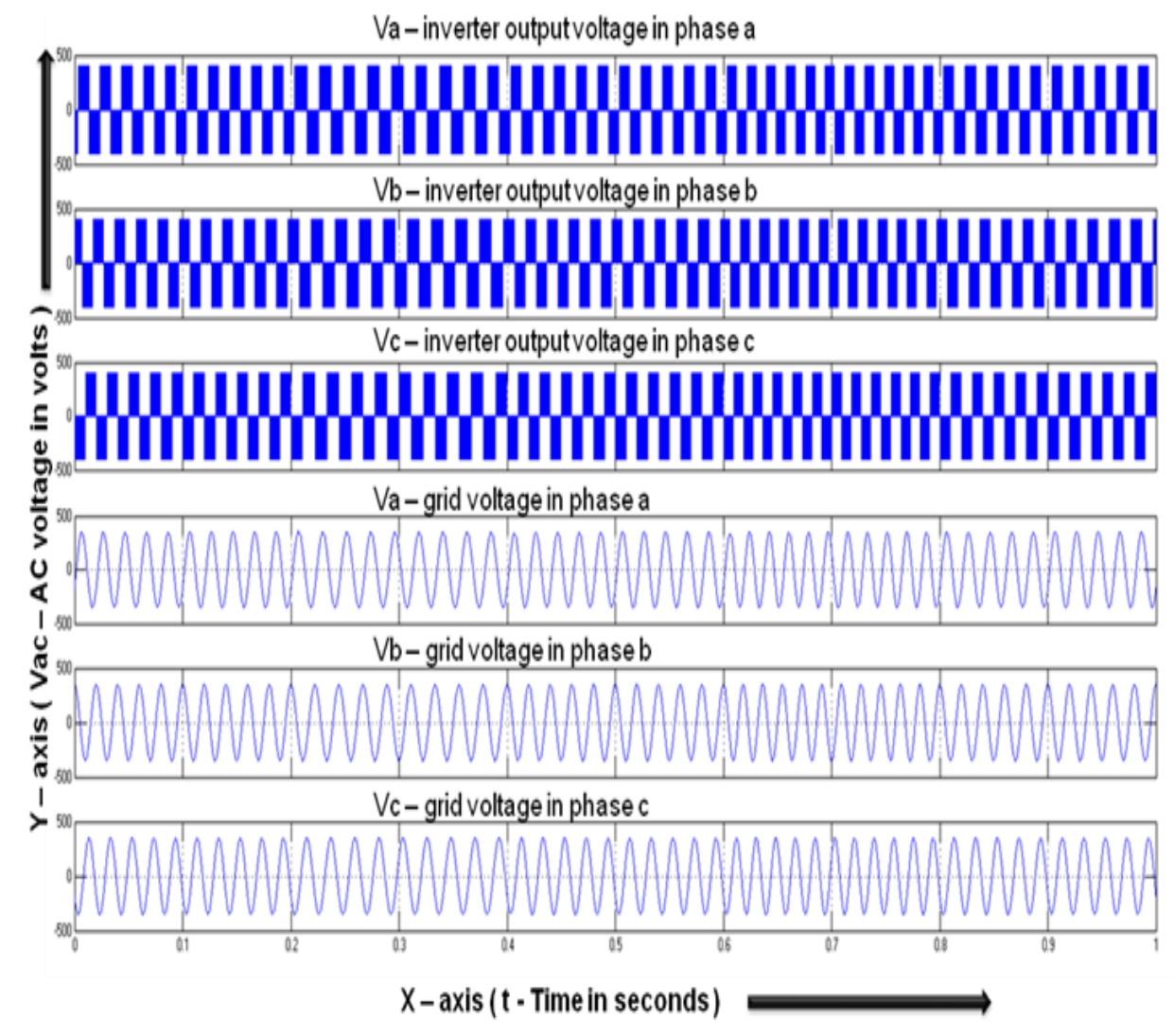

Fig 10 Simulation result of integrated grid inverter 


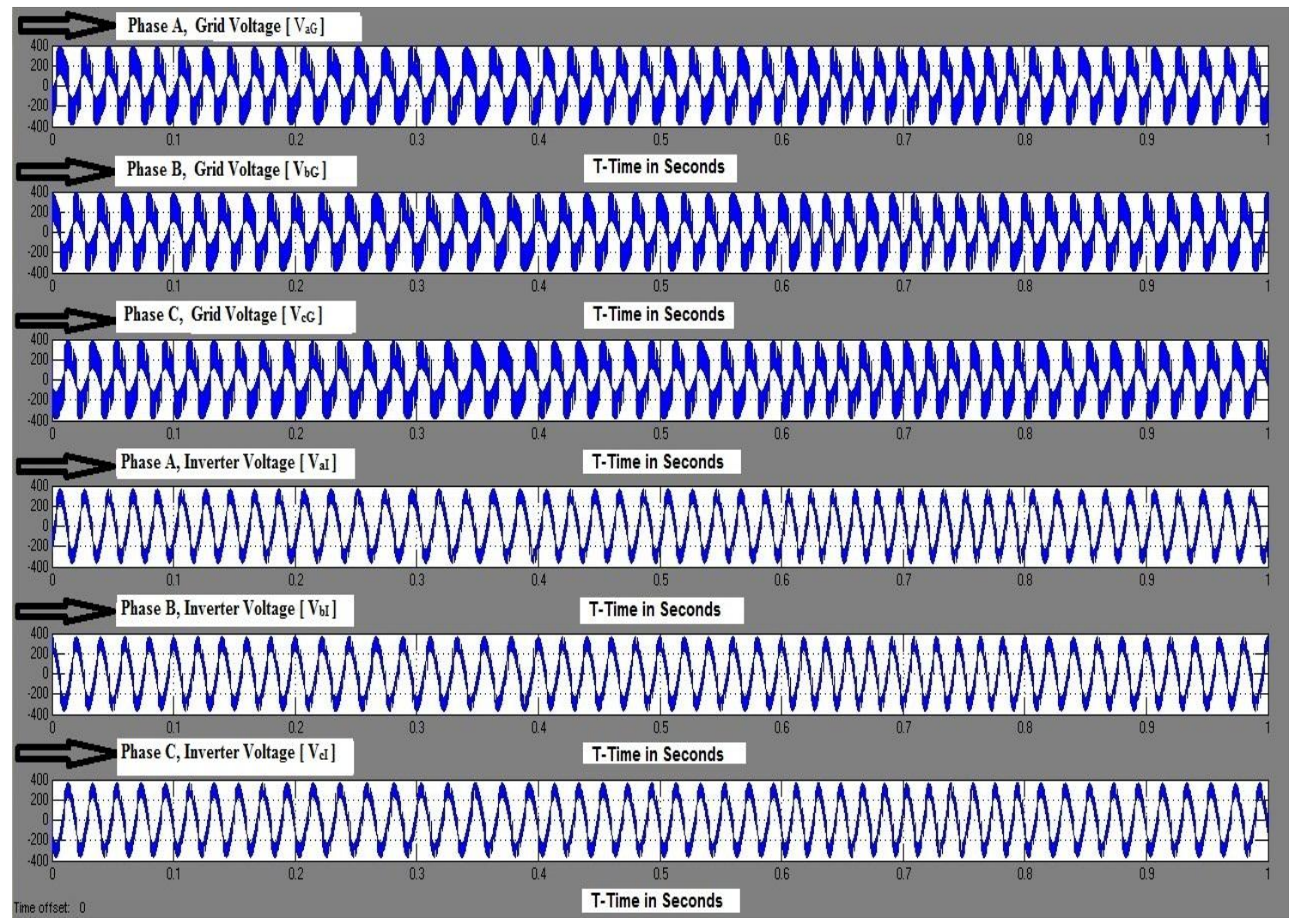

Fig 11 Simulation results of Grid Voltage $\left[\mathrm{V}_{\mathrm{G}}\right]$ for Phase $\mathrm{a}, \mathrm{b}, \mathrm{c}\left[\mathrm{V}_{\mathrm{aG}}, \mathrm{V}_{\mathrm{bG}}, \mathrm{V}_{\mathrm{cG}}\right]$ at $\mathrm{T}=1 \mathrm{sec}$ \& Inverter Voltage $\left[\mathrm{V}_{\mathrm{I}}\right]$ for Phase a,b,c $\left[\mathrm{V}_{\mathrm{al}}, \mathrm{V}_{\mathrm{bI}}, \mathrm{V}_{\mathrm{cI}}\right]$ at $\mathrm{T}=1 \mathrm{sec}$

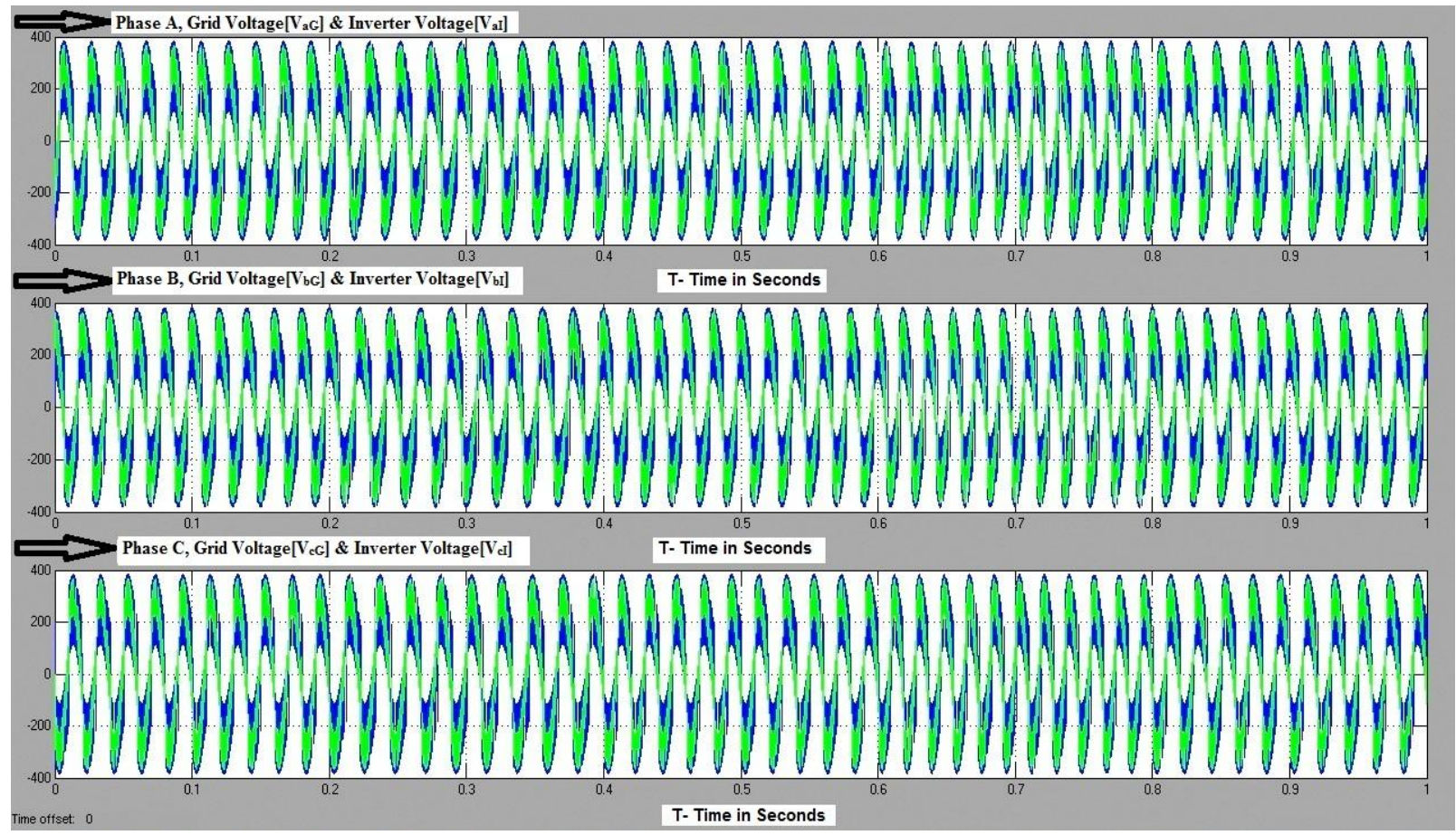

Fig 12 Simulation results of Grid Voltage $\left[\mathrm{V}_{\mathrm{G}}\right]$ \& Inverter Voltage $\left.\mathrm{V}_{\mathrm{I}}\right]$ for Phase a,b,c, $\left[\mathrm{V}_{\mathrm{aG}} \& \mathrm{~V}_{\mathrm{aI}}, \mathrm{V}_{\mathrm{bG}} \& \mathrm{~V}_{\mathrm{bI}}, \mathrm{V}_{\mathrm{cG}} \& \mathrm{~V}_{\mathrm{cI}}\right]$ at $\mathrm{T}=1 \mathrm{sec}$ 


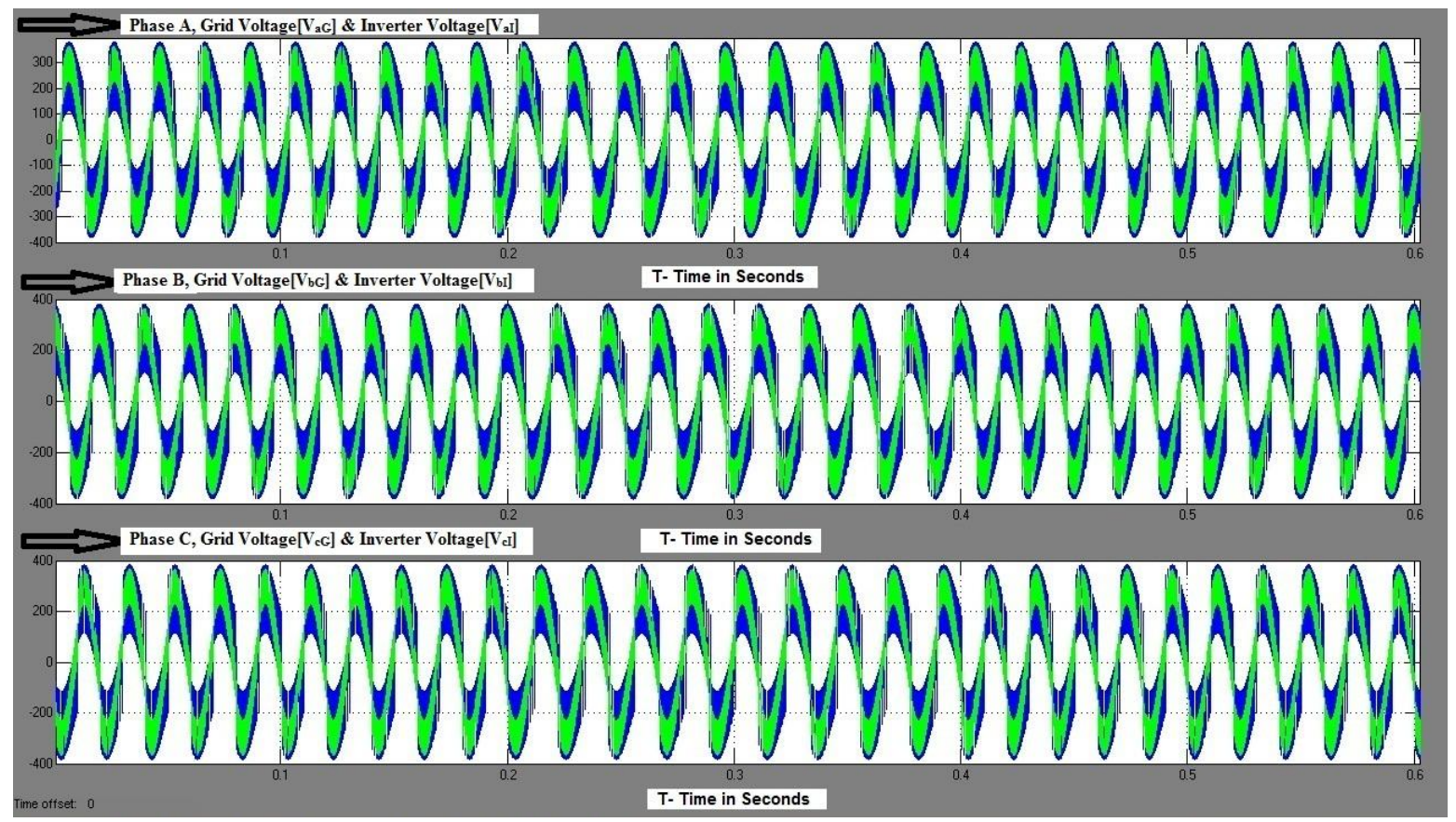

Fig.13. Simulation results of Grid Voltage $\left[\mathrm{V}_{\mathrm{G}}\right]$ \& Inverter Voltage[ $\left.\mathrm{V}_{\mathrm{I}}\right]$ for Phase $\mathrm{a}, \mathrm{b}, \mathrm{c},\left[\mathrm{V}_{\mathrm{aG}} \& \mathrm{~V}_{\mathrm{aI}}, \mathrm{V}_{\mathrm{bG}} \& \mathrm{~V}_{\mathrm{bI}}, \mathrm{V}_{\mathrm{cG}}\right.$ \& $\left.\mathrm{V}_{\mathrm{cI}}\right]$ at $\mathrm{T}=0$.6sec

The above Fig.12 \& Fig.13 shows the frequency match of Grid Voltage $\left[\mathrm{V}_{\mathrm{G}}\right]$ \& Inverter Voltage $\left[\mathrm{V}_{\mathrm{I}}\right]$ for Phase a,b,c at $\mathrm{T}=1$ second and $\mathrm{T}=0.6$ second respectively. Hence the proposed integrated inverter design corrects the frequency mismatch. Actually the inverter operates according to the grid frequency signal. So the system performs from unstable to stable condition. Thus the performance of grid as well as inverter frequency is enhanced.

\section{CONCLUSIONS}

The number of cycles per second in the grid as well as number of cycles per second in the inverter is equal under different load conditions at various time periods.Thus the proposed project regarding frequency control scheme using grid integrated inverter for wind mill applications effectively compromises the drawbacks. Mainly the frequencies mismatch in the existing systems by equalizing the frequencies difference between the grid as well as the inverter.

\section{REFERENCES}

[1]. G. M. Joselin Herbert, S. Iniyan, Ranko Goic, "Performance, reliability of wind farm in a developing country," Renewable Energy 35 (2010), 2739 - 2751, Elsevier LTD.

[2]. Narasimhan Santhanam, "Wind Energy in India Potential and Challenges," volume 5, issue 2, October 2011, RE Feature.

[3]. G. M. Joselin Herbert, S. Iniyan, E. Sreevalsan, S. Rajapandian, "A Review of Wind Energy Technologies,"
Science Direct, Renewable and Sustainable Energy Reviews 2007, (1117 - 1145).

[4]. M. R. Nouni, S. C. Mullick, T.C. Kandpil, "Techno Economics of Small Wind Electric Generator Projects for Decentralised Power Supply in India," Energy Policy 35 (2007) 2491 - 2506, Elsevier LTD.

[5]. Muhammad Khalid, Andrey V. Savkil, "Model Predictive Control for Wind Power Generation Smoothing with Controlled Battery Storage," IEEE Conference on Decission and control and 28th Chinese Control Conference, December $16-18,2009$.

[6]. MD.Enamuel Haque,Michael Negnevisty,Kashem M.muttaqi."A Novel Control Strategy for a Variable Speed Wind Turbine With a Permanent Magnet Synchronous Generator," IEEE Transaction on Industry Application, Volume 46,No.1,January / February 2010.

[7]. Gillian Lalor, Alan Mullane, Mark O' Malley,"Frequency Control and Wind Turbine Technologies," IEEE transaction on Power Systems, volume 20, No. 4, November 2005.

\section{BIOGRAPHIES}

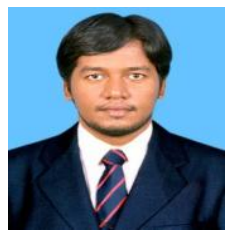

Mr.J.Vikramarajan received his Master degree in Power Electronics and Drives and Bachelor degree in Electrical and Electronics Engineering from VIT University, India. His research interests are power electronic applications, power quality, power electronic converters and power electronic controllers for renewable energy systems. 